\title{
FUSION AND VISUALISATION OF THE COLOR AND LONG WAVE INFRARED IMAGES OF VEGETATION FIRES
}

\author{
Slavica Ćosović Bajić \\ Tehničko veleučilište u Zagrebu
}

\begin{abstract}
The aspects of the image fusion and visualization of the color and long wave images are considered in the frame of the airborne reconnaissance and surveillance of the vegetation fires. The main constrains are consequence of the aerial platforms used: a) small lightweight aerial model (less than $5 \mathrm{~kg}$, altitude up to $300 \mathrm{~m}$ above mean ground level, radius limited by visibility), b) helicopter or fixed wings piloted airplane. Although the measurements of the forest fire temperature are not reliable (unknown emissivity), its indication is possible and the fusion of the color image and the long wave infrared image seems the most suitable solution for firefighting commander.
\end{abstract}

\section{INTRODUCTION}

The wild vegetation fires are very serious problem in many European and other worldwide countries. Many scientific and technology demonstration projects were realized aimed to support forest fires prevention and forest fire fighting. The overview of the remote sensing application in forest (vegetation) fires fighting and prevention was given in [1], one example of the concept of the integrated early detection and suppression in [2]. The seriousness of the forest (vegetation) fires in the Republic of Croatia in years $1992-2007$, [3], initiated national efforts in several domains related to forest fires, [4], [5], and [6]. Our attention is focused on the aspects of the image processing and analysis in the frame of the airborne reconnaissance and surveillance of the vegetation fires whereas two kinds of the aerial platforms are considered. They are: a) small lightweight aerial model (less than $5 \mathrm{~kg}$, altitude up to $300 \mathrm{~m}$ above mean ground level, radius limited by visibility), b) helicopter or fixed wings piloted airplane, [4]. The small lightweight aerial model (in accordance to the legal restrictions in Croatia (and in many other countries) is not unmanned aerial vehicle (UAV) and its use in firefighting activities has no legal obstacles, while for UAVs the legal obstacles are unavoidable. Due to limitations of the payload and autonomy of the small aerial models, a single sensor or a dual sensor system is typical solution (the color camera and the long wavelengths infrared "thermal" camera) and the images are transmitted by analogue microwave link. The consequence is a loss of the radiometric dynamics.

If larger aerial platform is used, the full potentials of the sensors can be used and processing can be accomplished onboard of the platform. This aspect of the fire fighting is not operationally developed at the satisfying level and we try to support solutions of several needs. In the paper we consider several aspects of the fusion and visualisation of the color and long wave infrared images of the vegetation fires, of the color images of the vegetation fires, as a part of the airborne surveillance and reconnaissance of the vegetation fires. The fusion of the color and long wave infrared images of general objects was reported in [7], the current paper is focused only to the images of the fire. The problems of the measurement of the elements of the forest fires are considered in [8], the application of the computer vision techniques for forest fire perception in [9].

\section{MEASUREMENT OF THE TEMPERATURE OF THE FOREST FIRE}

A forest fire (or a wild fire or a vegetation fire) is described in http://en.wikipedia.org/wiki/Forest fire "A wildfire front is the portion sustaining continuous flaming combustion, where unburned material meets active flames, or the smoldering transition between unburned and 
burned material. As the front approaches, the fire heats both the surrounding air and woody material ... First, wood is dried as water is vaporized at a temperature of $100{ }^{\circ} \mathrm{C}$, then pyrolyzed around $230^{\circ} \mathrm{C}$ to release flammable gases, then the wood will either smolder around $380^{\circ} \mathrm{C}$ or ignite around $590^{\circ} \mathrm{C}$ ". In accordance to [10], typical temperatures of the forest fires are nearly following values: smolder without the flame $370{ }^{\circ} \mathrm{C}$, a bright fire emitting the light $590{ }^{\circ} \mathrm{C}$, very strong flame $860^{\circ} \mathrm{C}$. In other references are mentioned similar and the higher temperatures too. The energy measured by sensor Wm presents part of the energy of the heat source Wo, $\mathrm{Wm}=$ $\varepsilon$ Wo, where $0<\varepsilon<=1$ is emissivity. The emissivity of the particular elements of the wild forest fires is different and also it is not known. Thus the measurement of the radiated energy has low accuracy and the reliability if only single band sensor is used. Application of two sensors, one in mid infrared wavelengths 3 $-5 \mu \mathrm{m}$ and the other in the wavelengths $8-14$ $\mu \mathrm{m}$ could overcome this problem [8] and is a perspective for larger aerial platforms. For the lightweight aerial models the combination of the color camera and the long wave infrared camera is the most suitable solution for operations in the field, where it supports firefighting commander in the near real time. A dual sensor on board of a small aerial model provides two kinds of imagery, color images in the visible wavelengths $(0.4$ to $0.7 \mu \mathrm{m})$ and a long wavelengths infrared images (usually 8 $14 \mu \mathrm{m})$. The firefighters can understand and simply extract information from the color images. The experience of use the color sensors onboard a small aerial model was collected in Croatia through several years (Mr. M. Hucaljuk, from 2003 to 2008), [4] in the dedicated surveillance demonstration campaigns. The long wave infrared images cannot reliably measure temperatures (due to lack of data about the emissivity) although can indicate their different values.

\section{FEATURES OF THE VEGETATION FIRE EXTRACTABLE IN COLOR IMAGE}

The simplest, the cheapest sensor onboard of the lightweight aerial model is the color camera that provides images in the red $-r$, green $-\mathrm{g}$, blue - b channels, Fig. 1 .

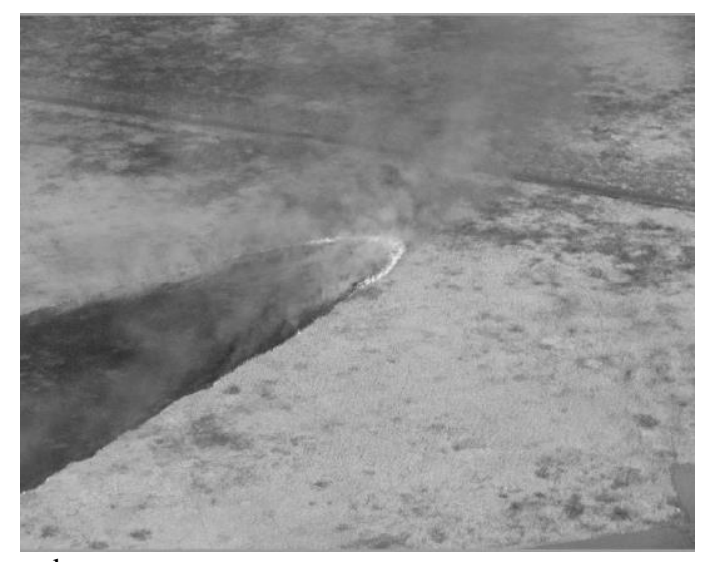

red

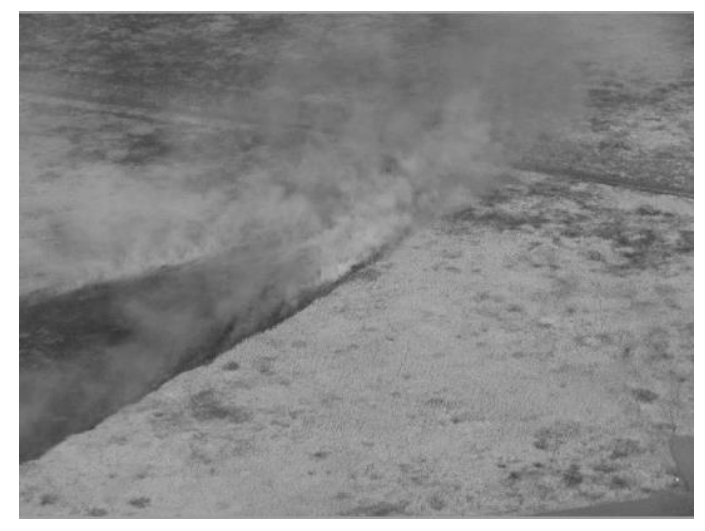

green

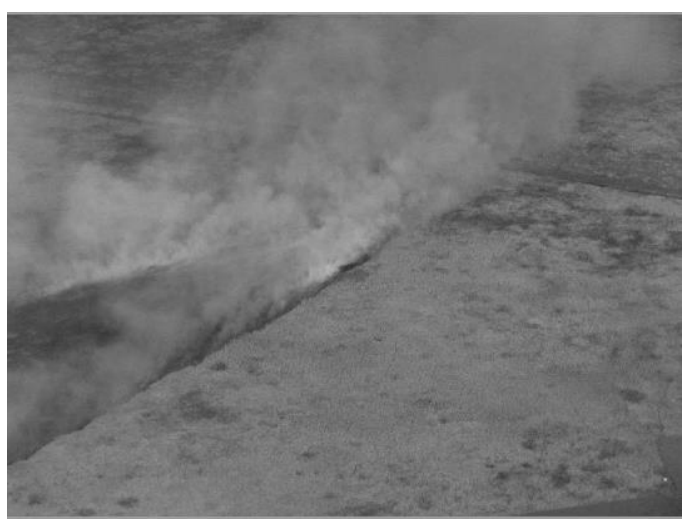

blue

Figure 1. Components red - $r$, green - $g$ and blue - $b$ of the color image of the fire. Aerial color image of the grass fire acquired in March 2009.

The segmentation of the color image that shows vegetation fire, if not covered by the fume, enables to determine main several elements of the fire: line of the fire front, burned area, unburned fuel area, see the concept given in [9]. While the red component shows the brightest parts of the fire, a simple difference of the red and green components, $r$ $\mathrm{kg}$, Fig. 2. or red and blue r-kb, k=1.0 to 1.3, enhances burned area. The fire front line can be derived if instead of raw $\mathrm{r}, \mathrm{g}, \mathrm{b}$ components, principal components Pc1, Pc2 and Pc3 are 
derived and $\mathrm{Pc} 3$ is used in further processing, Fig. 3. Comparison of the Pc3 (Fig. 3) and the red component (Fig. 1) shows that third principal component enhances a fire line. If we apply some filtering the fire line can become better defined, example at Fig. 4. In conclusion, the combination of the information contained in Fig. 2 and Fig. 4 provides valuable information to the firefighter commander, one about fire front line and one about the burned area.

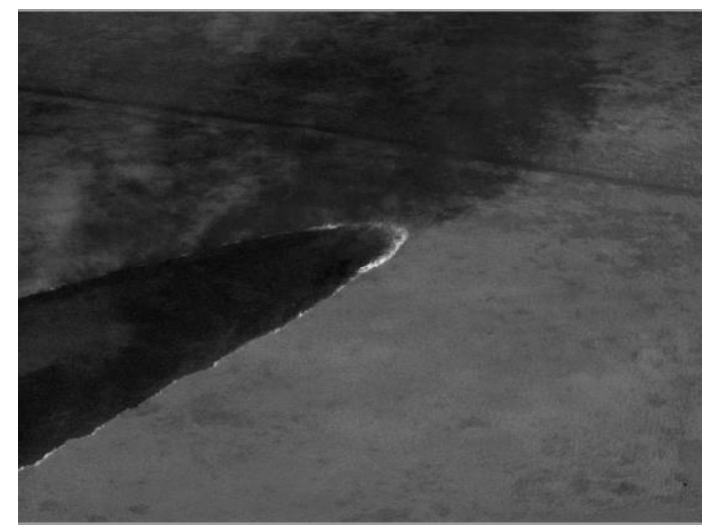

Figure 2. Difference r-kg, k=1.2.

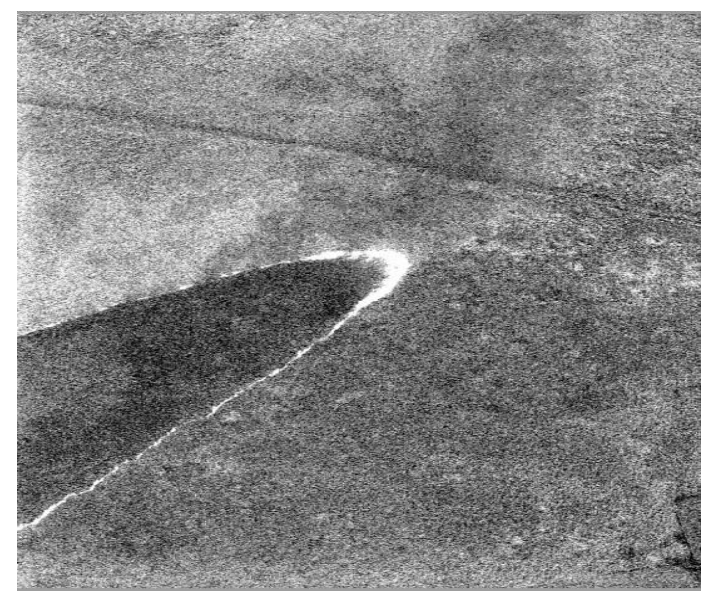

Figure 3. Third principal component Pc3.

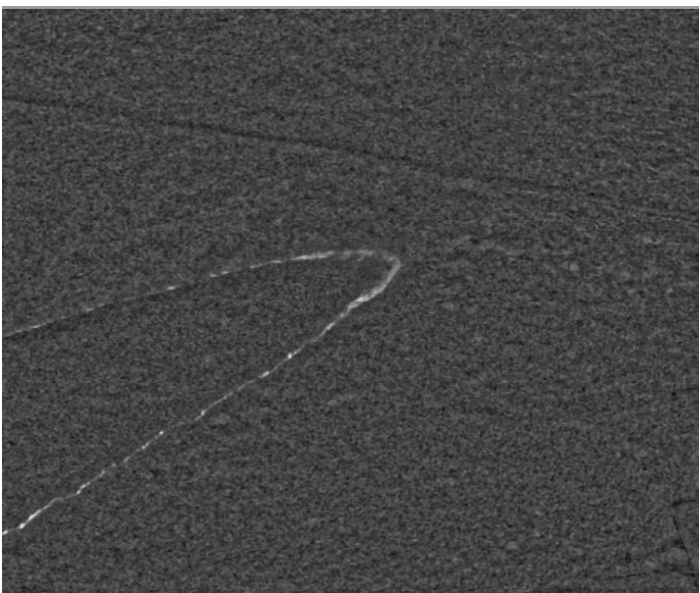

Figure 4. Median filter and local contrast adjustment provides border of the fire line.

\section{FUSION OF THE INFORMATION CONTAINED IN COLOR AND THE LONG WAVE INFRARED IMAGES OF THE VEGETATION FIRES}

The fusion of the information contained in a long wave infrared and the color images can be accomplished by several different methods, for pixel level fusion see [7].

In our analysis, the color image (Fig. 5) and the long wave infrared image (Fig. 6) of the controlled fire of the wood and the grass were used.
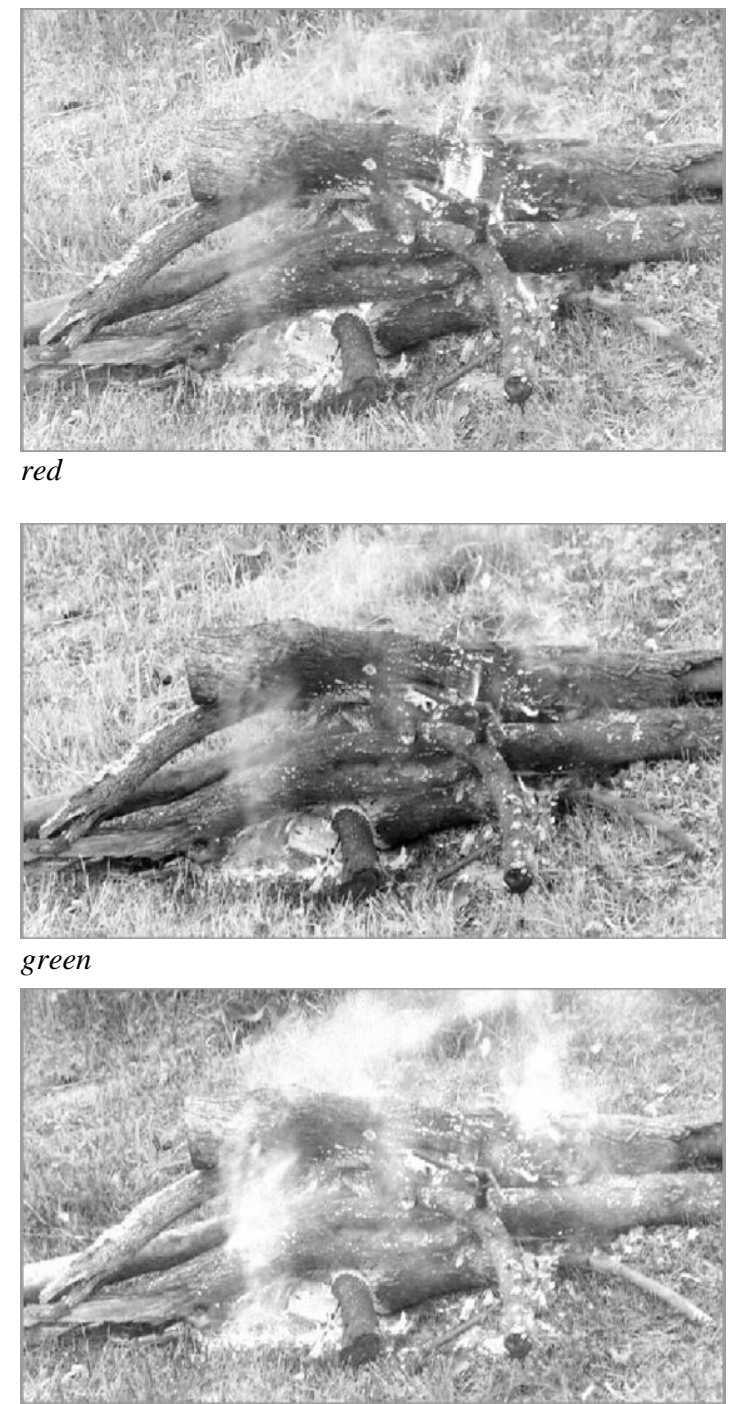

blue

Figure 5. Components of the color image of the fire. 


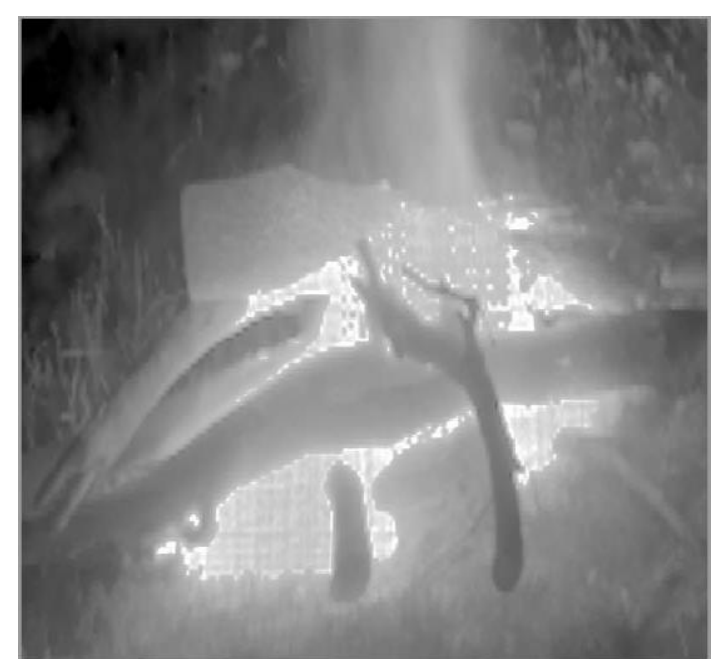

Figure 6. The long wave infrared ("thermal") of the fire shown in Fig. 5.

Images were registered and resampled and a common part was used in the further analysis [7]. The color image Fig. 5 provides general information about the scene and enables the firefighters' commander to identify elements of the scene. The long wave infrared image contains valuable information about the distribution of the heat temperature (see comments in section 2. about measurements). There are several ways how to combine these images a) show long wave infrared image in a grey scale or in the color palette, together with color image; b) show long wave infrared image in grey scale with lines of the constant values indicating the temperature; c) calculate principal components of the color image and a long wave infrared image and use negative of the first principal component, the second, the third and the fourth principal component together with red, green and blue components as the layers for unsupervised classification, Fig. 7; d) calculate the lines of the constant values indicating the temperature from the long wave infrared image and show them over the color image.

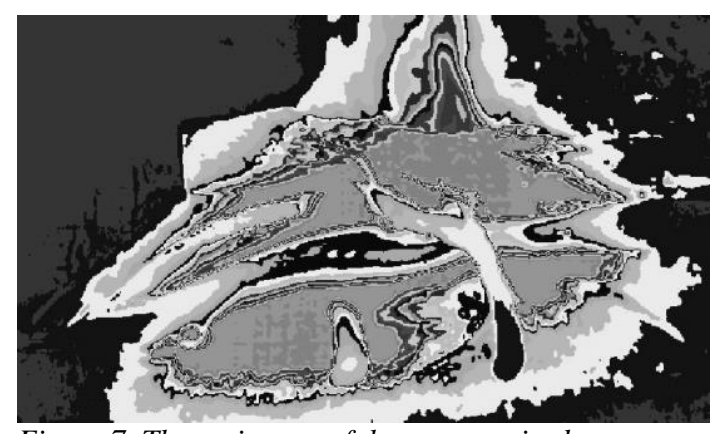

Figure 7. Thematic map of the unsupervised

classification in twenty classes of the following input rasters: components red, green, blue of the color image, long wave infrared image, second, third and the forth principal component derived from long wave infrared and the components of color image, negative of the firstprincipal component. Note: original image is in color.

\section{VISUALIZATION OF THE FUSED IMAGES}

After the analysis of different kinds of the visualization, we concluded that the most usable version can be color image with overlaid lines indicating the temperature. Two examples Fig. 8 and Fig. 9, show low and high values of the indicators of the temperature. The same range of indicating values of temperature shown overlaid on the long wave infrared images, Fig. 10 support the former conclusion conclusion.

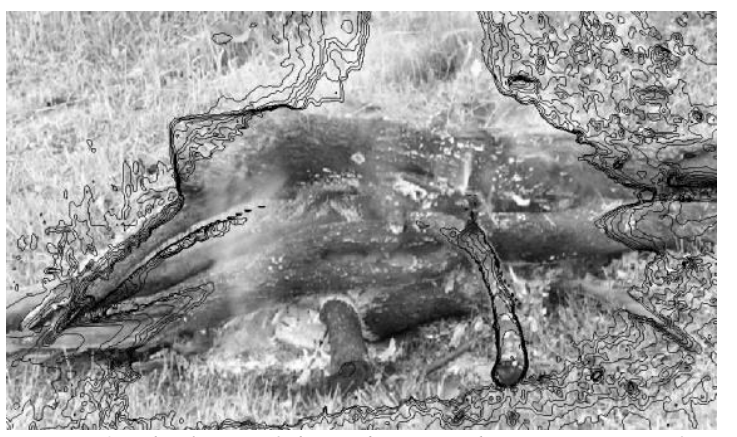

Figure 8. The lines of the indicating the temperature from 100 to 500 shown over the color image. Note: original image is in color.

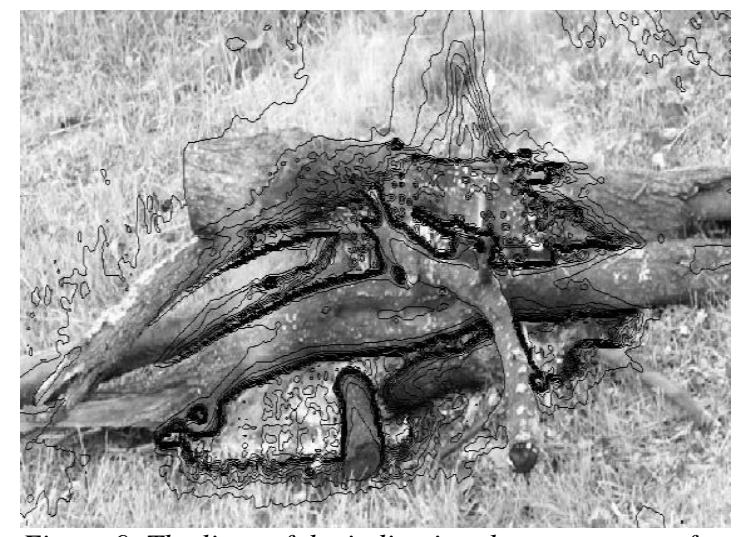

Figure 9. The lines of the indicating the temperature from 1000 to 10000 shown over the color image. Note: original image is in color. 


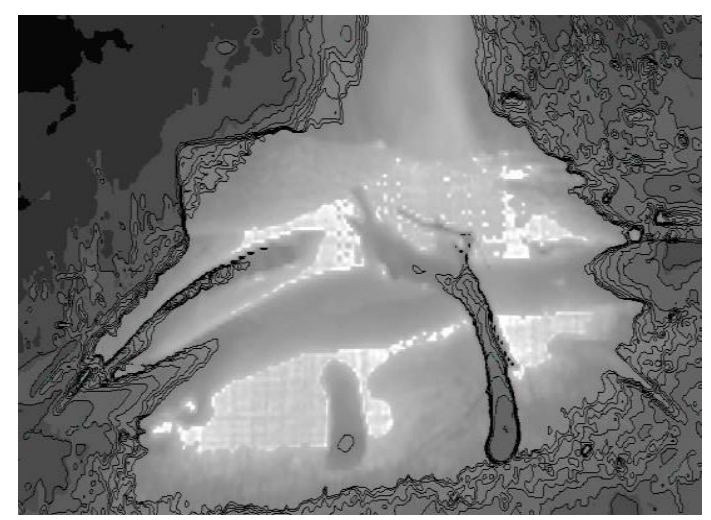

Figure 10. The lines of the indicating the temperature from 100 to 500 shown on a long wave infrared image.

\section{DISCUSSION}

Two approaches to derivation of the indicated temperature of a wild forest fire were analyzed. One is to derive contour lines of the intensity of the long wave infrared image and show them overlaid over the color image, Fig. 8, Fig. 9. The second approach is to apply unsupervised classification in large number of classes, Fig. 7. and results of both approaches are similar, Fig.

11.

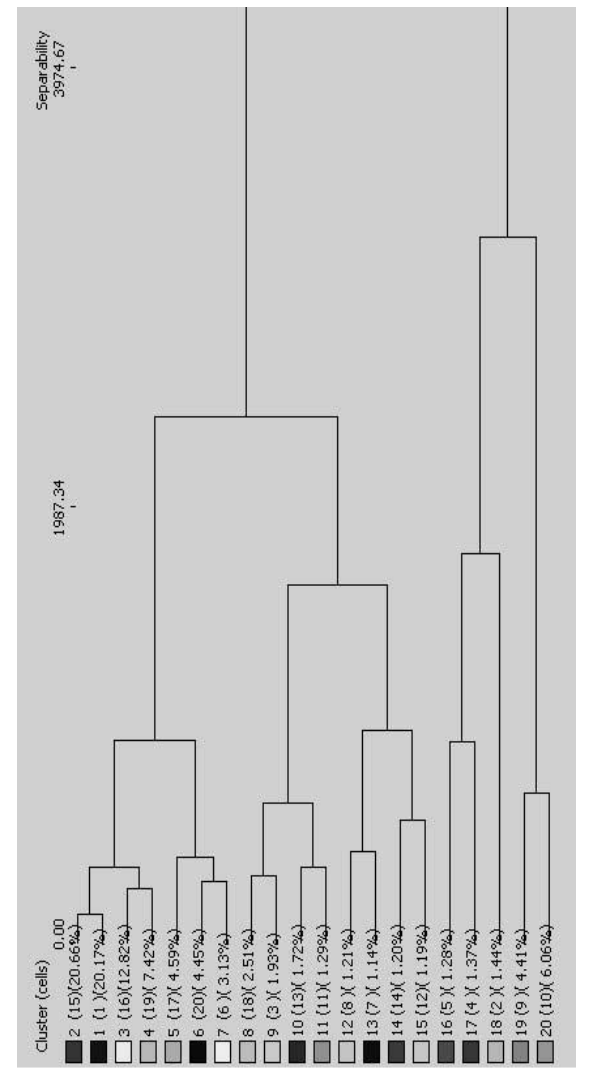

Figure 11. Dendrogram of the classification shown on Fig. 7. Maximum separability is 7949 , only part of the separability lower than 3974 is shown .
If compared classes in dendrogram from the left to the right side $(2,1,3,4 \ldots .20)$ in Fig. 11 and classes in the thematic map Fig. 7 and the contour lines on Fig. 8 and Fig. 9, expected agreement of the borders is visible. This agreement can happen if the number of classes in the unsupervised classification equals the number of the intervals of the contour lines. What will be applied depends on the availability of the implemented algorithms for mentioned operations.

\section{CONCLUSIONS}

The goal of the analysis was to find out the methods of the fusion the information contained in the airborne color image and the long wave infrared image of the wild forest fire that is suitable for use by firefighter commander is realized. The constrains of the aerial light weight model preferred use of the simple color camera and the long wave infrared "thermal" camera. The proposed solution is to derive lines that indicate the fire temperature and overlaid them over the color image. While the system with considered sensors is in use in Croatia, we expect further development of the fusion and the visualization.

\section{ACKNOWLEDGEMENTS}

The presented results were obtained in the frame of the scientific project "Electromagnetic compatibility - the protection of the environment", funded by the Ministry of the science, education and sports of the Republic of Croatia.

\section{REFERENCES}

[1] E. Chuvieco, 2008., Current potentials and problems of using Remote Sensing methods in forest fires prevention and assessment, Disaster Management and Emergency Response in the Mediterranean Region, Oluić (ed.), First EARSeL Conference 2008, Zadar, Croatia, pp. $3-16$.

[2] W. Kruell, R. Tobera, I. Willms, 2008., An integrated approach for early forest fire detection and suppression, Disaster Management and Emergency Response in the Mediterranean 
Region, Oluić (ed.), First EARSeL Conference 2008, Zadar, Croatia, pp. $55-64$.

[3] P. Jurjević, D. Vuletić, J. Gračanin, G. Seletković, 2008., Forest fires in the Republic of Croatia (1992-2007), Disaster Management and Emergency Response in the Mediterranean Region, Oluić (ed.), First EARSeL Conference 2008, Zadar, Croatia, pp. 43-54.

[4] M. Bajić, M. Miloslavić, M. Hucaljuk, N. Šosterič, D. Penzar, 2008., "Airborne reconnaissance and surveillance of the vegetation fires", Disaster Management and Emergency Response in the Mediterranean Region, Oluić (ed.), First EARSeL Conference 2008, Zadar, Croatia, pp. $99-109$.

[5] System for the multisensor airborne reconnaissance and surveillance in crisis situations and the protection of the environment, technological project TP-06/0007-01, Croatian Ministry of sciences, education, sports; Faculty of Geodesy and Faculty of transport and traffic sciences University of Zagreb, HCR Centre for testing, development and training Ltd. Zagreb, Pastor Group J.S.Co,. Zagreb, 2007 - 2009. (In Croatian).

[6] M. Bajić, H. Gold, T. Fiedler, D. Gajski, 2008., "Development of the concept from 1998. and realisation in 2007. - 2008. of the system for the airborne multisensor recconnaissance and surveillance in the crisis situations and the protection of the environment",
Disaster Management and Emergency

Response in the Mediterranean

Region, Oluić (ed.), First EARSeL

Conference 2008, Zadar, Croatia, pp. 401410.

[7] A. Krtalić, M. Bajić, 2007.,"'Fusion of long wave thermal infrared and visible near infrared aerial images",

Procedings of the conference Geoinformation in Europe, Bolzano June 2007., M. Gomarasca (ed.), 2007 Millpress, Netherlands, pp. 497-503.

[8] C. Justice, L. Giglio, L. Boschetti, D. Roy, I. Csiszar, J. Morisette, Y. Kaufman, 2006., Algorithm Technical

[9] J. Beck, 2004., Capabilities of airborne infrared remote sensing systems to detect hotspots, Advantage, Vol. 5, No. 11 ,

Slavica Ćosović Bajić , osobni podatci su na stranici 62. 